\title{
FUEL COMPOSITION EFFECTS ON NATURAL GAS VEHICLE EMISSIONS
}

by

Christopher F. Blazek, John Grimes, and Patricia Freeman Institute of Gas Technology

Brent K. Bailey and Christopher Colucci

National Renewable Energy Laboratory

Paper Presented at the 207th ACS National Meeting-Division of Fuel Chemistry San Diego Hyatt Hotel

March 13-17, 1994

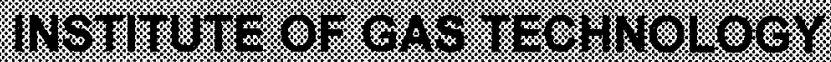

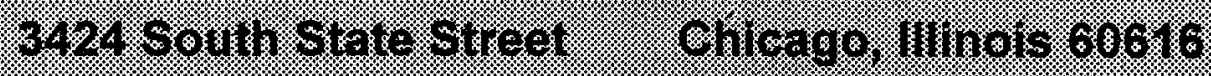
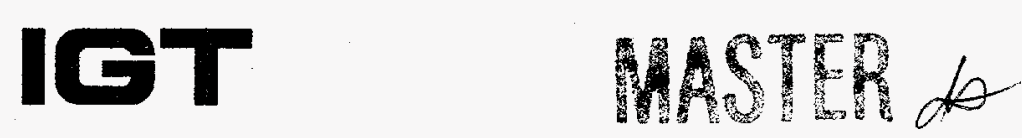


\section{DISCLAIMER}

This report was prepared as an account of work sponsored by an agency of the United States Government. Neither the United States Government nor any agency thereof, nor any of their employees, make any warranty, express or implied, or assumes any legal liability or responsibility for the accuracy, completeness, or usefulness of any information, apparatus, product, or process disclosed, or represents that its use would not infringe privately owned rights. Reference herein to any specific commercial product, process, or service by trade name, trademark, manufacturer, or otherwise does not necessarily constitute or imply its endorsement, recommendation, or favoring by the United States Government or any agency thereof. The views and opinions of authors expressed herein do not necessarily state or reflect those of the United States Government or any agency thereof. 


\section{DISCLAIMER}

Portions of this document may be illegible in electronic image products. Images are produced from the best available original document. 


\title{
FUEL COMPOSITION EFFECTS ON NATURAL GAS VEHICLE EMISSIONS
}

\author{
Christopher F. Blazek, John Grimes, and Patricia Freeman \\ Institute of Gas Technolog; , Chicago, Illinois 60632 \\ Brent K. Bailey and Christopher Colucci \\ National Renewable Energy Laboratory
}

Keywords: $\quad$ Natural Gas Vehicles, Natural Gas Composition, NGV Emissions

\begin{abstract}
Under a contract from DOE's National Renewable Energy Laboratory (NREL) and support from Brooklyn Union Gas Company (BUG), Northern Illinois Gas Co., the Institute of Gas Technology (IGT) evaluated four state-of-the-art, electronic, closed-loop natural gas vehicle (NGV) conversion systems. The systems included an Impco electronic closed-loop system, Mogas electronic closed-loop system, Stewart \& Stevenson's GFI system, and an Automotive Natural Gas Inc. (ANGI) Level I electronic closed-loop conversion system. Conversion system evaluation included emission testing per $40 \mathrm{CFR}$ Part 86, and driveability. All testing was performed with a 1993 Chevy Lumina equipped with a $3.1 \mathrm{~L}$ MPFI V6 engine. Each system was emission tested using three different certified compositions of natural gas, representing the 10th, mean and 90 th percentile gas compositions distributed in the United States. Emission testing on indolc: 2 was performed prior to conversion kit testing to establish a base emission value. Indolene testing was also performed at the end of the project when the vehicle was converted to its OEM configuration is ensire that the velicle's emissions wer: not altered during testing. The results of these tests will be presented.
\end{abstract}

\section{INTRODUCTION}

A number of conversion systems are commercially available to convert gasoline fueled vehicles to either dedicated or bi-fueled natural gas vehicles (NGVs). This paper presents the research results to date of four NGV conversion systems tested on the 1993 3.1L MPFI Chevrolet Lumina passenger car. This study included fuel emission testing based on the Federal Test Procedure (FTP) per 40 CFR Part 86 and fuel economy measurements using three different compositions of natural gas. Emission testing on indolene was performed prior to conversion system testing to establish gasoline base emission values. Any variations in emissions or fuel economy related to fuel quality will be better understood as a result of the FTP emission testing program. In addition to fuel quality, this investigation also evaluated conversion system performance, both in terms installation and driveability. All procedures required to convert the gasoline fueled vehicle to compressed natural gas (CNG) were fully documented including hardware installation, electronic hookups, and system calibration.

\section{SPECIFICATION OF NATURAL GAS COMPOSITION}

Natural gas is not pure methane or a homogeneous mixture, but varies in composition by location and seasonally. Variations occur between the originating fields and may be further modified due to processing prior to transmission. Additional mixing of different gases also occurs during pipeline transmission. As a result, natural gas does not describe a single type of fuel or a narrow range of characteristics, unlike gasoline or diesel fuel which is manufactured within certain specifications.

Fuel composition can affect vehicle emissions. The most recent work on natural gas composition was completed in 1991 by the American Gas Association Laboratories with the Institute of Gas Technology as a subcontractor, under Gas Research Institute funding. ${ }^{1}$ The research focused on the mean average, minimum, maximum, 10 th percentile, and 90 th percentile gas fractions. However, information reported in the GRI sponsored study for the mean, 10th percentile, and 90th percentile values for cach of the component gases allowed for only a pseudo-composition to be developed. For example, the 10 percentile value of methane could be combined with the 90 th percentile values of the other constituents for a minimum-methane concentration natural gas. The rationale for this approach is that, when methane dominates the composition, the other gases would be expected to be at their lower values. However, this does not take into account that natural gas compositions are not manufactured but occur normally with certain relationships between each of the components. As a result, IGT concluded that a more detailed review was necessary to determinc representative natural gis compositions.

Two primary factors that impact emissions and directly describe the general characteristics of naiural grs include the concentration of methane and the Wobbe number. The methane concentration is a good measure because it is the dominant component in natural gas. The Wobbe number is a measure of the fuel energy flow rate through a fixed orifice under given inlet conditions. It is calculated as the ratio of the higher heating value divided by the square root of the specific gravity. Variations in Wobbe number of the gas will produce similar variations in the air-fuel ratio for gas metering systems used on vehicles. Variability of this parameter will most significantly affect engines equipped with open-loop controls, where the exhaust oxygen cannot be sensed and adjusted. In general, the Wobbe number is a good criteria for natural gas because it correlates well with the ability of an internal combustion engine to use a particular gas. It also takes into account many of the gas components because it is a bulk property.

The first step was to determine the minimum, maximum, mean average, median, 10 th percentile, and 90th percentile values for the methane mole fraction, as shown in Table 1. This data represents over 
6,000 gas samples taken from various locations throughout the continental U.S. It should be noted that the minimum value represcuts propane/air peakshaving gas. This gas is generated by many local utilities during severe periods of high uemand which typically occur cluring the coldest periods of the year. During mild winters these plants may not even be used and during normal winters plants may only operate 1 to 2 days per year. The equivalent values for the Wobbe number are shown in Table 2.

TABLE 1. METHANE FRACTION ANALYSIS

$\begin{array}{ll}\text { Minimum: } & 55.8 \% \\ \text { Maximum: } & 98.1 \% \\ \text { Mean (avg): } & 93.0 \% \\ \text { Std Deviation: } & 4.5 \% \\ \text { Median: } & 94.9 \% \\ \text { 10th Percentile: } & 84.1 \% \\ \text { 90th Percentile: } & 96.3 \%\end{array}$

TABLE 2. WOBBE NUMBER ANALYSIS

$\begin{array}{ll}\text { Minimum: } & 1202.6 \\ \text { Maximum: } & 1418.7 \\ \text { Mean (avg): } & 1329.4 \\ \text { Std Deviation: } & 42.6 \\ \text { Median: 1347.0 } & \\ \text { 10th Percentile: } & 1233.0 \\ \text { 90th Percentile: } & 1358.5\end{array}$

Having identified the methane fraction and Wobbe number values to be used, the next step was to define a suitable method of calculating the mole fractions of each of the other components. Because of the inherent variability of an individual natural gas sample, it was unlikely that a representative composition could be formulated from just the few values that fit exactly on the selected Wobbe number values. To select a slightly wider, more representative range of natural gas compositions at a given valuc, the avcrage of each of the components was calculated considering only those samples within 2 Wobbe number counts of the identified Wobbe number. These results are shown in Table 3 (values presented are mole \%). The near equivalency between methane fraction and Wobbe number for the natural gas composition can be seen in comparing the resulting averages for each of the components in each of the desired ranges. For example, the methane and Wobbe number for the two 10th percentile compositions are fairly close, 83.84 mole \% vs. 83.96 mole \% and 1229.76 vs. 1232.97 . This holds true for the other components. Although there is more variability within the mean and 90 th percentile compositions, the differences are within the variations that may be seen throughout the year.

TABLE 3. COMPOSITION BASED ON WOBBE NUMBER

\begin{tabular}{llll} 
& $10 \%$-ile & Mean & $90 \%$-ile \\
\hline METHANE & 83.96 & 92.87 & 94.80 \\
ETHANE & 5.72 & 3.34 & 3.03 \\
PROPANE & 1.07 & 0.63 & 0.58 \\
I-BUTANE & 0.09 & 0.07 & 0.10 \\
N-BUTANE & 0.11 & 0.12 & 0.13 \\
I-PENTANE & 0.03 & 0.04 & 0.05 \\
N-PENTANE & 0.01 & 0.03 & 0.03 \\
C6+ & 0.03 & 0.05 & 0.07 \\
NITROGEN & 6.05 & 2.07 & 0.56 \\
CO & 1.40 & 0.78 & 0.65 \\
O $_{2}$ & 1.53 & 0.00 & 0.00 \\
WOBBE & 1232.97 & 1329.15 & 1358.61
\end{tabular}

Because fuel metering is a critical factor in all NGV conversion systems, both IGT and NREL agreed that the gas compositions based on the Wobbe number, as presented in Table 3, should be used for the test fuels. High pressure gas cylinders were then prepared for each of the three compositions and certified by IGT for use in this test program.

\section{BASELINE EMISSION TEST}

IGT leased a new 1993 Chevy Lumina 3.1 liter MPFI V6 (VIN\# 2GIWN54T7P9146384) for the testing program. During December of 1992 and January of 1993 the vehicle was driven 5,000 mostly highway miles on gasoline to ensure proper engine break-in and catalyst aging. An inspection was performed on the Lumina at 4,803 to establish baseline parameters prior to emission testing and conversion.

FTP emission testing on indolene were initiated in March, 1993 per 40 CFR Part 86 on the Chevy Lumina. Two baseline indolene tests were performed with the dynamometer set for a 3,500 pound inertia and $6.0 \mathrm{ahp}$. The vehicle odometer read 6,410 miles. The test results are presented in Table 4. As can be seen from the test results, the vehicle passed the exhaust emissions and shed test. Weighted total hydrocarbon values were 0.23 and 0.27 , carbon monoxide 2.74 and 2.84 , nitrous oxides 0.48 and 0.49 , carbon dioxide 489 and 491 , respectively reported in grams per mile, with fuel economy for both tests at $18.0 \mathrm{mpg}$. The shed test results were 0.34 and 0.39 grams respectively.

\section{CNG EMISSION TEST RESULTS}

All systems were installed and setup according to the manufacturer's instruction. Following the installation, a test drive and dynamometer set-up were performed using a snap-on analyzer for ECM parameters. Power valve and idle adjustment were performed to minimize tailpipe emissions (through the converter) without sacrificing driveability. Following these adjustments, IGT conducted driveability tests following the CRC Report No. 577 "1990 CRC Driveability Workshop" recommendations 
published in October 1990.2 All four systems passed the driveability tests with no faults and did not experience engine stalling or hesitation, nor any problems with starting.

\section{TABLE 4. EXHAUST AND EVAPORATIVL INDOLENE EMISSIONS DATA}

\begin{tabular}{|c|c|c|}
\hline \multicolumn{3}{|l|}{ Test Fuel } \\
\hline & $3 / 12 / 93$ & $3 / 15 / 93$ \\
\hline Vehicle Odometer, miles & 6410 & 6429 \\
\hline \multicolumn{3}{|l|}{ Exhaust Emission Results } \\
\hline \multicolumn{3}{|l|}{ Cold Transient, grams } \\
\hline THC $\left(\mathrm{C}_{3} \mathrm{H}_{8}\right.$ calibration $)$ & 2.65 & 3.15 \\
\hline $\mathrm{CH}_{4}$ (a) & 0.22 & 0.26 \\
\hline NMHC (a) & 2.40 & 2.85 \\
\hline $\mathrm{CO}$ & 23.24 & 26.97 \\
\hline $\mathrm{NO}_{\mathrm{x}}$ & 4.25 & 3.95 \\
\hline $\mathrm{CO}_{2}$ & 1741 & 1767 \\
\hline Fuel Economy, MPG & 17.9 & 17.6 \\
\hline \multicolumn{3}{|l|}{ Cold Stabilized, grams } \\
\hline THC $\left(\mathrm{C}_{3} \mathrm{H}_{8}\right.$ calibration $)$ & 0.34 & 0.25 \\
\hline $\mathrm{CH}_{4}(\mathrm{a})$ & 0.12 & 0.12 \\
\hline NMHC (a) & 0.20 & 0.11 \\
\hline $\mathrm{CO}$ & 4.70 & 4.32 \\
\hline $\mathrm{NO}_{\mathrm{X}}$ & 1.14 & 1.21 \\
\hline $\mathrm{CO}_{2}$ & 1992 & 2004 \\
\hline Fuel Economy, MPG & 17.9 & 17.0 \\
\hline \multicolumn{3}{|l|}{ Hot Transient, grams } \\
\hline THC $\left(\mathrm{C}_{3} \mathrm{H}_{8}\right.$ calibration $)$ & 0.45 & 0.74 \\
\hline $\mathrm{CH}_{4}$ (a) & 0.13 & 0.14 \\
\hline NMHC (a) & 0.29 & 0.57 \\
\hline $\mathrm{CO}$ & 9.82 & 8.99 \\
\hline $\mathrm{NO}_{\mathrm{x}}$ & 1.02 & 1.22 \\
\hline $\mathrm{CO}_{2}$ & 1533 & 1536 \\
\hline Fuel Economy, MPG & 20.5 & 20.5 \\
\hline \multicolumn{3}{|l|}{ Weighted Total, grams / mile } \\
\hline $\mathrm{THC}\left(\mathrm{C}_{3} \mathrm{H}_{8}\right.$ calibration $)$ & 0.23 & 0.27 \\
\hline $\mathrm{CH}_{4}$ (a) & 0.04 & 0.04 \\
\hline NMHC (a) & 0.19 & 0.22 \\
\hline $\mathrm{CO}$ & 2.74 & 2.84 \\
\hline $\mathrm{NO}_{\mathrm{x}}$ & 0.48 & 0.49 \\
\hline $\mathrm{CO}_{2}$ & 489 & 491 \\
\hline Fuel Economy, MPG & 18.0 & 18.0 \\
\hline \multicolumn{3}{|l|}{ Shed, grams } \\
\hline Diurnal 0.12 & 0.20 & \\
\hline Hot Soak & 0.22 & 0.19 \\
\hline Total 0.34 & 0.39 & \\
\hline
\end{tabular}

All emission tests were performed at the AutoResearch Laboratories per 40 CFR Part 86 . The dynamometer was set for a 3,500 pound inertia and 6.0 ahp. The preliminary test resuits for the MOGAS system as tested in April, 1993 are presented in Table 5 for the three different gas compositions. From the weighted total results, it became vlear that the vehicle was set-up lean following Mogas's set-uj) instructions. IGT did not attempt to optimize the emission results during set-up. However, the results do indicate that $\mathrm{NO}_{\mathrm{X}}$ emissions could be reduced running richer, and thereby increasing carbon monoxide emissions which are currently significantly below the limit. It should be noted that for the 10th percentile gas the system did not pass the 1993 EPA NOx limit of $1.0 \mathrm{gr} . \mathrm{mile}$.

The preliminary test results for the Impco system as tested in May, 1993 are presented in Table 6. As was the case with the MOGAS system, the weighted total test results indicate that the vehicle was set-up lean following Impco's set-up instructions. IGT did not attempt to optimize the emission results during set-up. Again, the results indicate that $\mathrm{NO}_{\mathrm{X}}$ emissions could be reduced running richer, and thereby increasing carbon monoxide emissions which are currently significantly below the limit. However, the system met all applicable 1993 EPA emission standards for the entire range of natural gas compositions tested.

The preliminary test results for the GFI system as tested in July, 1993 are presented in Table 7. From weighted total results for the mean gas composition, it became clear that the vehiclc was set-up rich by the GFI provided software. The carbon monoxide average $(4.04 \mathrm{~g} / \mathrm{mile})$ was above the $3.4 \mathrm{~g} . / \mathrm{mile}$ EPA limit. However, the results do indicate that $\mathrm{CO}$ emissions could be reduced running leaner, and thereby increasing NOx emissions which are currently significantly below the limit. Since the software version supplied by GFI is specific to the 1993 Lumina tested, software changes may be required to "recalibrate" the vehicle.

The weighted total results for the 90th and 10th percentile gas compositions further confirmed that the vchicle was set-up rich by the GFI provided set-Lp sofiware. However, a closer analysis of the test results by IGT indicated that the 90 th and the 10 th percentile gas composition tests did not concur with 
the repeatability guidelines set forth in the publication "Statistical Design and Analysis Methods for the Auto/Oil Air Quality Research Program" as published by Painter and Rutherford in SAE paper 920319.3 Of the tests reported, the $\mathrm{HC}, \mathrm{CO}$, and $\mathrm{NO}_{\mathrm{X}}$ cold stabilized test pairs and the $\mathrm{HC}$ weighted total values from the 90th percentile gas composition did not meet this criteria. Likewise for the tests conducted on 10th percentile gas composition, the $\mathrm{NO}_{X}$ and $\mathrm{HC}$ cold transient test pairs and the $\mathrm{HC}, \mathrm{CO}$, and $\mathrm{NO}_{X}$ hot transient pairs also werc above the limiting ratios. Further investigation indicated that an "air leak" in the testing equipment miy have been a contributing cause to these differences.

As a result of this discrepancy noted above, a third test was performed for just the 90th and 10th percentile gas compositions to verify that the "air leak" was corrected and to provide further correlation of the test results. The data ior these additional tests are summarized in Table 7 along with the previous test data. As can be seen, the 90th and 10th percentile "third" test data agree more closely to the "first" tests performed on each composition. However, based on the Auto/Oil reference sited above, IGT took the recommended approach of averaging the three tests for the average values reported for the 90 th and 10th percentile gas composition tests.

Based on the average values for cach of the gas compositions, the GFI system failed the CO emissions test based on the $1993 \mathrm{CO}$ standard of $3.4 \mathrm{~g} / \mathrm{mi}$. However, two factors must be taken into consideration when assessing the GFI system. Both the related NOx emission values and the system setup requirements and system sophistication. Unlike the previous two systems tested, the GFI system requires information about the gas composition during vehicle setup and calibration. For this test IGT used the system default values and did not attempt to "dial in" the gas composition for each of the three gas compositions tested. Since the other two systems were not "tuned" on each composition, it was decided that this would give the GFI system an advantage. Second, and even more important, unlike the other systems, the GFI system incorporates a built in learning algorithm in the electronic controls which gradually adjusts the fuel/gas mixture in response to operating parameters such as exhaust oxygen sensor output relative to load. This learning adjustment occurs gradually during normal driving. However, due to the nature of the emission testing, the vehicle was not driven between tests to allow the system to adjust to the new fuel composition. Because of the cost of the certified test fuel, driving between tests was not deemed practical. Since the GFI system incorporates an adaptive learning electronic control system, given enough time on a given gas composition, this system may have passed all of the emission standards. The very low and consistent NOx levels of the GFI system also suggest that this system may have the capability of meeting 1994 standards, even on the 1993 test vehicle

The preliminary test results for the ANGI system as tested in October, 1993 are presented in Table 8. From weighted total results for the mean gas composition, the average levels of $\mathrm{CO}$ and $\mathrm{NO}_{\mathrm{X}}$ emissions are well below the current EPA limits. The weighted totals for the 10 th percentile composition indicate that the ANGI system failed the current $N O_{X}$ standard of $1.0 \mathrm{~g} / \mathrm{milc}$. This indicates that the system produced very low cmission levels with the mean composition gas, but the 10 th percentilc composition caused the system to run too lean.

The test results for the 90th percentile gas composition for the levels of $\mathrm{CO}$ did not concur with the repeatability guidelines set forth in the Auto/Oil reference. Again, based on Auto/Oil recommendations, a third test was performed. The results of the second and third tests were within recommended limits. Since there was a possibility of high background levels of $\mathrm{CO}$ during the first test and since the second and third test results were in close agreement, the first test was treated as an outlier and the average results were taken from tests 2 and 3 . Thus, the weighted total test results for the 90 th percentile were well within the EPA limits for $\mathrm{CO}$ and NOX. This indicates that the ANGI system operates well on the mean and 90th percentile compositions which have a higher methane content, but the system fails current EPA limits on $\mathrm{NO}_{X}$ emission levels when operating with 10th percentile gas composition fuel.

\section{CONCLUSIONS}

As can be seen from these results, the Mogas system produced the lowest carbon monoxide test results followed by the Impco, ANGI and GFI systems. The GFI system actually failed the CO emissions test based on the $1993 \mathrm{CO}$ standard of $3.4 \mathrm{~g} / \mathrm{mi}$. However, two factors must be taken into consideration when assessing the GFI system. Unlike the other 2 systems, the GFI system requires information about the gas composition during vehicle setup and calibration. For this test IGT used the system default values and did not attempt to "dial in" the gas composition for each of the three gas compositions tested. Since the other two systems were not "tuned" on each composition, it was decided that this would give the GFI system an advantage. Second, and even more important, unlike the other systems, the GFI system incorporates a built in learning algorithm in the electronic controls which gradually adjusts the fuel/gas mixture in response to operating parameters such as exhaust oxygen sensor output relative to load. This learning adjustment occurs gradually during normal driving. However, due to the nature of the emission testing, the vehicle was not driven between tests to allow the system to adjust to the new fuel composition. Because of the cost of the certified test fuel, driving between tests was not deemed practical. 
TABLE 5. MOGAS SYSTEM EMISSIONS SUMMARY

Fuel Type Mean CNG

Vehicle Odometer, miles

6821

Exhaust Emission Results

Weighted Total, grams / mile

THC $\left(\mathrm{CH}_{4}\right.$ calibration $)$

$\mathrm{CH}_{4}$ (a)

NMHC (a)

$\mathrm{CO}$

$\mathrm{NO}_{\mathrm{X}}$

$\mathrm{CO}_{2}$

Fuel Economy, MPG

$1.41 \quad 1.40$

$1.40 \quad 1.42$

$0.16 \quad 0.11$

$0.39 \quad 0.19$

$0.85 \quad 0.90$

$363 \quad 357$

$18.9 \quad 19.1$

Fuel Type 90th Percentile CNG

Vehicle Odometer, miles

6858

6869

Exhaust Emission Results

Weighted Total, grams / mile

$\mathrm{THC}\left(\mathrm{CH}_{4}\right.$ cailibration $)$

$\mathrm{CH}_{4}$ (a)

$\mathrm{NMHC}$ (a)

$\mathrm{CO}$

$\mathrm{NO}_{\mathrm{x}}$

$\mathrm{CO}_{2}$

Fuel Economy, MPG

1.28

1.22

0.16

0.59

0.79

351

19.2

1.37

1.34

0.09

0.28

0.83

355

10th Percentile CNG

Fuel Type

10th miles

6898

6910

Exhaust Emission Results

Weighted Total, grams / mile

THC $\left(\mathrm{CH}_{4}\right.$ calibration $)$

$\mathrm{CH}_{4}$ (a)

NMHC (a)

$\mathrm{CO}$

$\mathrm{NO}_{\mathrm{X}}$

$\mathrm{CO}_{2}$

Fuel Economy, MPG

TABLE 6. IMPCO SYSTEM EMISSIONS SUMMARY

Mean CNG

Vehicle Odometer, miles

7309

Exhaust Emission Results

Weighted Total, grams / mile

$\mathrm{THC}\left(\mathrm{CH}_{4}\right.$ calibration)
$\mathrm{CH}_{4}$ (a)
$\mathrm{NMHC}$ (a)
$\mathrm{CO}$
$\mathrm{NO}_{x}$
$\mathrm{CO}_{2}$
Fuel Economy, MPG

1.01

1.03

1.11

1.01

0.04

0.80

0.82

379

0.05

0.54

0.83

376

Fuel Economy, MPG

$18.1 \quad 18.2$

Fuel Type 90th Percentile CNG

Vehicle Odometer, miles

7280

7291

Exhaust Emission Results

Weighted Total, grams / mile $\mathrm{THC}\left(\mathrm{CH}_{4}\right.$ calibration $)$

$\mathrm{CH}_{4}$ (a)

NMHC (a)

$\mathrm{CO}$

$\mathrm{NO}_{\mathrm{X}}$

$\mathrm{CO}_{2}$

Fuel Economy, MPG

0.97

1.04

1.10

1.03
0.05

1.10
0.04

$1.74 \quad 1.31$

$0.57 \quad 0.63$

$378 \quad 373$

Fuel Type

10th Percentile CNG

Vehicle Odometer, miles

Exhaust Emission Results

Weighted Total, grams / mile THC ( $\mathrm{CH}_{4}$ calibration)

$\mathrm{CH}_{4}$ (a)

NMHC (a) 
TABLE 7. GFI SYSTEM EMISSIONS SUMMAKY

Fuel Type Mean CNG

Vehicle Odometer, miles

7620

$763 \hat{n}$

Exhaust Emission Results

Weighted Total, grams / mile

THC ( $\mathrm{CH}_{4}$ calibration)

$\mathrm{CH}_{4}$ (a)

NMHC (a)

(a)

$\mathrm{NO}_{\mathrm{x}}$

$\mathrm{CO}_{2}$

Fuel Economy, MPG

1.31

$1.30 \quad 1.26$

$0.08 \quad 0.07$

$4.16 \quad 3.92$

$0.18-0.22$

$389 \quad 394$

$17.3 \quad 17.1$

Fuel Type 90th Percentile CNG

Vehicle Odometer, miles

Exhaust Emission Results

Weighted Total, gr. / mile

$\mathrm{THC}\left(\mathrm{CH}_{4}\right.$ calibration $)$

$\mathrm{CH}_{4}$ (a)

NMHC (a)

$\mathrm{CO}$

$\mathrm{NO}_{\mathrm{x}}$

$\mathrm{CO}_{2}$

Fuel Economy, MPG

Fuel Type 10th Percentile CNG ,

Vehicle Odometer, miles

Exhaust Emission Results

Weighted Total, gr. / mile

THC ( $\mathrm{CH}_{4}$ calibration)

$\mathrm{CH}_{4}$ (a)

NMHC (a)

$\mathrm{CO}$

$\mathrm{NO}_{x}$

$\mathrm{CO}_{2}$

Fuel Economy, MPG
7650

7661

7854

1.27

1.20

0.07

4.27

0.22

373

17.8

7691

1.05

1.07

0.08

3.40

0.23

395

18.5
7710

7873

0.77

0.79

0.05

2.56

0.19

378

17.7

1.18

1.36

0.05

4.05

0.27

382

17.4

1.04

1.01
0.07

3.16

0.19

377

19.4

1.00

1.02

0.07

3.36

0.26

386

18.9

\section{TABLE 8. ANGI SYSTEM EMISSIONS SUMMARY}

Fuel Type

Mean CNG

Vehicle Odometer, miles

8610

8621

Exhaust Emission Results

Weighted Total, grams / mile

THC ( $\mathrm{CH}_{4}$ calibration)

$\mathrm{CH}_{4}$ (a)

NMHC (a)

$\mathrm{CO}$

$\mathrm{NO}_{\mathrm{x}}$

$\mathrm{CO}_{2}$

Fuel Economy, MPG

0.52

$0.49 \quad 0.52$

$0.04 \quad 0.03$

$\begin{array}{ll}1.40 & 1.29\end{array}$

0.11

384

0.12

$\begin{array}{ll}37.9 & 17.8\end{array}$

Fuel Type 90th Percentile CNG

Vehicle Odometer, miles

Exhaust Emission Results

8670

8681

8808

Weighted Total, $\mathrm{g} / \mathrm{mile}$

THC ( $\mathrm{CH}_{4}$ calibration)

$\mathrm{CH}_{4}$ (a)

NMHC (a)

$\mathrm{CO}$

$\mathrm{NO}_{\mathrm{x}}$

$\mathrm{CO}_{2}$

Fuel Economy, MPG

0.78

0.82

0.04

5.05

0.09

397

8681

0.54

0.53

0.03

1.95

392

17.2

0.56

0.58

0.05

1.60

0.10

394

Fuel Type 10th Percentile CNG

Vehicle Odometer, miles

$8632 \quad 8651$

Exhaust Emission Results

Weighted Total, g/mile

THC $\left(\mathrm{CH}_{4}\right.$ calibration $)$

$\mathrm{CH}_{4}$ (a)

NMHC (a)

$\mathrm{CO}$

$\mathrm{NO}_{\mathrm{x}}$

$\mathrm{CO}_{2}$

Fuel Economy, MPG

$\begin{array}{ll}0.92 & 0.92 \\ 0.94 & 1.06 \\ 0.06 & 0.06 \\ 0.23 & 0.24 \\ 1.09 & 1.46 \\ 387 & 428 \\ 19.1 & 17.2\end{array}$

(a) CNG Tests: Methane concentration is based on independent GC analysis. NMHC calculation from $\mathrm{GC}$ speciation analysis. 
With respect to the average NOx emission level, the GFI system produced the lowest NOx test results for all compositions followed by the Impco and Mogas systems. The ANGI system produced even lower levels of NOx emissions with the mean and 90th percentile gas compositions, but did not pass the 1993 NOx standard of $1.0 \mathrm{~g} / \mathrm{mi}$ with the 10 th percentile gas composition fuel. The Impco and GFI systems passed the NOx standard while the Mogas system was slightly over the limit. In assessing these results one must take into consideration the system setup procedure. Both the Impco, and Mogas systems involved subjective tuning of the system to achieve low tailpipe emissions based on the use of a 4 gas analyzer. The subjective nature of the setup as well as the system sensitivity resulted in a lean mixture for all three of these conversion systems. This produced a combination of relatively low $\mathrm{CO}$ and high NOx, as would be expected. On the other hand, the GFI and ANGI systems calibrate themselves automatically, producing the opposite effect. This automatic rich setup produced surprisingly consistent low NOx values for each of the gas compositions tested, resulting in NOx emissions below both the 1993 and 1994 emission limits, except where noted above.

\section{ACKNOWLEDGMENT}

IGT would like to thank Mr. Brent Bailey and Mr. Chris Colucci at the U.S. Department of Energy, National Renewable Energy Laboratory for both their patience and support during this program. Special thanks goes to Ms. Heide Swanson and Mr. Wilson Tomala at Brooklyn Union Gas for stipporting the testing of a fourth conversion system. Other organizations that contributed to the success of this program include the Northern Illinois Gas Company, Amoco, the Gas Research Institute and AutoResearch Laboratory as well as the cooperation of the equipment suppliers.

\section{REFERENCES}

1. W.L. Liss, W.H. Thrasher, G.F. Steinmetz, P. Chowdiah, and A. Attari, "Variability of Natural Gas Composition in Select Metropolitan Areas of the United States" Gas Research Institute Report No. GRI-92/0123; March 1992.

2. "1990 CRC Driveability Workshop", CRC Report No. 577 October, 1990.

3. Painter, Rutherford, "Statistical Design and Analysis Methods for the Auto/Oil Air Quality Research Program", SAE paper 920319. 